\title{
Correction to: 11 th International Conference PLANT FUNCTIONING UNDER ENVIRONMENTAL STRESS September 12-15, 2018, Cracow, Poland
}

Published online: 13 December 2018

(c) Franciszek Górski Institute of Plant Physiology, Polish Academy of Sciences, Kraków 2018

Correction to: Acta Physiologiae Plantarum (2018) 40:193 https://doi.org/10.1007/s11738-018-2757-x

The original version of this article unfortunately contained a mistake. Title, author names and other details were incorrect in the XML. The corrected title is given below.

11th International Conference PLANT FUNCTIONING UNDER ENVIRONMENTAL STRESS September 12-15, 2018, Cracow, Poland.

The original article has been corrected. 